Issued by Sandia National Laboratories, operated for the United States Department of Energy by Sandia Corporation.

NOTICE: This report was prepared as an account of work sponsored by an agency of the United States Government. Neither the United States Government, nor any agency thereof, nor any of their employees, nor any of their contractors, subcontractors, or their employees, make any warranty, express or implied, or assume any legal liability or responsibility for the accuracy, completeness, or usefulness of any information, apparatus, product, or process disclosed, or represent that its use would not infringe privately owned rights. Reference herein to any specific commercial product, process, or service by trade name, trademark, manufacturer, or otherwise, does not necessarily constitute or imply its endorsement, recommendation, or favoring by the United States Government, any agency thereof, or any of their contractors or subcontractors. The views and opinions expressed herein do not necessarily state or reflect those of the United States Government, any agency thereof, or any of their contractors.

Printed in the United States of America. This report has been reproduced directly from the best available copy.

Available to DOE and DOE contractors from

U.S. Department of Energy

Office of Scientific and Technical Information

P.O. Box 62

Oak Ridge, TN 37831

Telephone: (865)576-8401

Facsimile: (865)576-5728

E-Mail: reports@adonis.osti.gov

Online ordering: http://www.doe.gov/bridge

Available to the public from

U.S. Department of Commerce

National Technical Information Service

5285 Port Royal Rd

Springfield, VA 22161

Telephone: (800)553-6847

Facsimile: (703)605-6900

E-Mail: orders@ntis.fedworld.gov

Online order: http://www.ntis.gov/ordering.htm

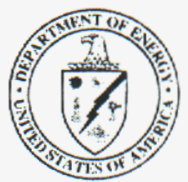


SAND2001-1736

Unlimited Release

Printed August 2001

\title{
Investigation of the Feasibility of RTL Concept for Fusion Energy
}

\author{
Craig L. Olson \\ Pulsed Power Sciences Center \\ Stephen A. Slutz \\ Target and Z-Pinch Theory Department \\ William A. Stygar and Rick B. Spielman \\ Z-Pinch Physics and Power Flow Department \\ Gary E. Rochau \\ Modeling and Simulation Department \\ Mark S. Derzon \\ Advanced Concepts \\ Sandia National Laboratories \\ P.O. Box 5800 \\ Albuquerque, NM 87185-1190 \\ Per F. Peterson \\ University of California, Berkeley \\ Berkeley, CA 94720 \\ John S. De Groot \\ University of California, Davis \\ Davis, CA 95616 \\ Gregory A. Rochau and Robert R. Peterson \\ University of Wisconsin \\ Madison, WI 53706
}

\begin{abstract}
Initial investigations of the feasibility of the RTL (Recyclable Transmission Line) concept of a rep-rated z-pinch IFE (Inertial Fusion Energy) power plant have been completed. This concept uses an RTL to provide the necessary standoff between the fusion target and the power plant chamber. The goal of these investigations was to
\end{abstract}


determine if the electrical breakdown characteristics of a candidate RTL material have a deleterious effect on the power flow efficiency to the load. Experiments were performed on the Saturn accelerator at a current of about $10 \mathrm{MA}$. The experiments were performed with a model RTL coaxial transmission line of diameter $8 \mathrm{~cm}$, length $30 \mathrm{~cm}$, and gap width $3 \mathrm{~mm}$. Candidate materials were stainless-steel (SS), SS with a 10 micron tin coating, aluminum, and aluminum with a 100 micron carbon coating. Stainless-steel was the reference material (SS is used on Z, but it is not appropriate for RTL applications because of activation effects). Aluminum was expected to emit non-uniformly, and therefore require a coating of carbon. A coating of tin on SS was tested to mimic a coating of tin on the power plant coolant material Flibe. Four Saturn shots were successfully fielded (two SS reference shots, one aluminum shot, and one tin-coated SS shot). The primary diagnostics were three sets of three azimuthally placed B-dots to measure the current. The results were better than expected: there was no indication of current loss in any of the RTL experiments. Supporting work was also performed by the University of California, Berkeley (study of RTL materials and shock mitigation), the University of California, Davis (direct magneto-hydrodynamic conversion), and the University of Wisconsin (RTL power plant concept refinement). These initial studies are very encouraging and support further development of the RTL rep-rated z-pinch power plant concept.

\section{Acknowledgments}

We gratefully acknowledge the experimental support of Chris Russell, John McKinney, Chris Jeffs, Terry Gilliland, Tim Wagoner, Brad Peyton, Rich Westfall, and the Saturn Crew for making the experiments possible. The interest and support of Jeff Quintenz, Keith Matzen, and Dillon McDaniel are gratefully acknowledged. This work was performed under an LDRD supported by Al Romig (V.P. 1000), Bob Eagan (V.P. 6000), and Gerry Yonas (V.P. 16000). 


\section{Contents}

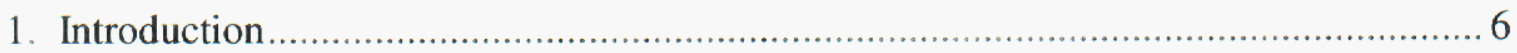

2. RTL candidate material experiments on Saturn ................................ 10

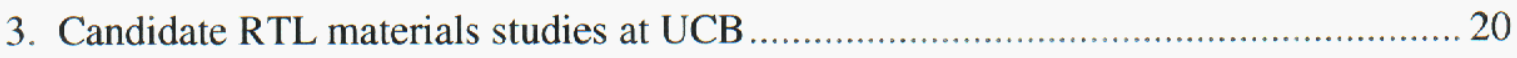

4. Direct MHD conversion concept at UCD .............................................................. 21

5. Rep-rated z-pinch power plant concept development at $\mathrm{U}$. Wisconsin ...................... 23



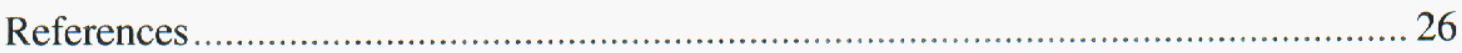

\section{Figures}

Figure 1. A schematic of a Recyclable Transmission Line (RTL) …............................. 8

Figure 2. A schematic of the Saturn RTL design........................................................ 11

Figure 3. The measured I-dot signals from shot 1 (stainless-steel RTL) ........................ 13

Figure 4. The integrated B-dot signals from shot 1 (stainless-steel RTL) ..................... 14

Figure 5. The azimuthally-averaged current for shot 1 (stainless-steel RTL) ................ 15

Figure 6. The measured I-dot signals for shot 2 (bare aluminum RTL) ........................ 16

Figure 7. The azimuthally-averaged currents for shot 2 (bare aluminum RTL)............ 17

Figure 8. The measured I-dot signals for shot 4 (tin-coated stainless-steel RTL) .......... 18

Figure 9. The azimuthally-averaged currents for shot 4 (tin-coated stainless-



Figure 10. Flibe ingot $(1.5 \mathrm{~cm}$ diameter) cast in quartz test tube. The tensile test structure was fabricated by potting with tin (top) and lead (bottom)

Figure 11. COG calculation of the (a) tritium breeding ratio, (b) energy conversion ratio, and (c) neutron shielding effectiveness 


\section{Introduction}

The $\mathrm{Z}$ machine at Sandia National Laboratories (SNL) is the most powerful multi-module synchronized pulsed-power accelerator in the world, and it routinely delivers up to 20 MA to a z-pinch load. Rapid development of $\mathrm{z}$-pinch loads on $\mathrm{Z}$ has led to outstanding progress in the last few years, resulting in radiative powers of up to 280 TW in $4 \mathrm{~ns}$ and a total radiated $\mathrm{x}$-ray energy of 1.8 MJ. The present goal of the Inertial Confinement Fusion (ICF) program for $\mathrm{Z}$ is to demonstrate single-shot, high-yield fusion capsules. Lasnex computer calculations indicate that a pulsed power machine delivering 55-60 MA could drive high yield ( $>0.5 \mathrm{GJ}$ ) fusion explosions. Pulsed power is a robust and inexpensive technology, which should be well suited for Inertial Fusion Energy (IFE), but a rep- rated capability is needed. This pulsed power based technology is efficient ( $>15 \%$ to $x$-rays) and much less expensive than other IFE driver technologies (such as lasers or heavy ion beams), and the capability to operate pulsed power reliably at high repetition rates has been demonstrated at small scale. However, a z-pinch driven fusion explosion will destroy a portion of the transmission line that delivers the electrical power to the z-pinch. On Z, these electrodes are constructed from stainless steel, and are expensive, and would be damaged if the z-pinch ignited a high yield inertial fusion capsule. The cost for the transmission line would outweigh the value of the energy created by the fusion explosion. Thus, up until recently, it has been assumed that this technology is limited to single-shot experiments.

However, recent developments have led to a viable conceptual approach for a reprated z-pinch power plant for IFE. This concept exploits the advantages of going to high yield (a few GJ) at low rep-rate $(\sim 0.1 \mathrm{~Hz})$, and using a Recyclable Transmission Line (RTL) to provide the necessary standoff between the fusion target and the power plant chamber. In this approach, a portion of the transmission line near the capsule is replaced after each shot. The RTL should be constructed of materials that can easily be separated from the liquid coolant stream and refabricated for subsequent shots. One possibility is that most of the RTL is formed by casting Flibe (a salt composed of fluorine, lithium, and 
beryllium, which is an attractive choice for the reactor coolant) with chemically compatible lead or tin on the surface to provide electrical conductivity. We estimate that fusion yields greater than $1 \mathrm{GJ}$ will be required for efficient generation of electricity. (For comparison, IFE power plant studies using heavy ions or lasers use yields of 0.4 0.7 GJ.) Calculations indicate that the first wall will have an acceptable lifetime with these high yields if blast mitigation techniques are used. Furthermore, yields above 5 GJ may allow the use of direct energy conversion.

The Recyclable Transmission Line (RTL) concept emerged at a workshop ${ }^{1}$ at Sandia National Laboratories and was developed further at the Snowmass Summer Study on Fusion Energy ${ }^{2}$ in 1999. The idea is to construct the final portion of the transmission lines which deliver current to the z-pinch out of material that can be recycled inexpensively. We shall refer to this portion of the transmission line as the RTL (Recyclable Transmission Line) as shown in Fig. 1. The labeled RTL portion of the transmission line will be blown up with each detonation of the capsule located within the z-pinch. Then the entire assembly will be replaced with a new one for the next detonation. A coaxial feed is shown with a dynamic hohlraum capsule. The use of doubled ended z-pinch driven hohlraum would require the use of a triaxial feed. The connection between the recyclable and the permanent part of the transmission line is at the top of the reactor chamber. Only a small portion of the first wall at the top of the containment chamber is shown. Notice that the vacuum interface does not see the blast directly and could be a large distance from the opening in the reactor chamber (the schematic is not to scale). The RTL could be constructed from wires, sheets, or cast. Wires have the advantage of easy alignment, but the anode side may form a source of ions when the wires explode. The use of thin sheets possibly strengthened by wires would not be as easy to align, but should not produce a source of ions on the anode side. The cost of constructing an RTL with these techniques should be approximately proportional to the total mass, e.g. stainless steel costs about $\$ 3 / \mathrm{kg}$. However, one could construct a very low mass RTL with these two approaches. Calculations indicate that a total mass less than $1 \mathrm{~kg}$ results in an acceptable amount of electrode motion in response to magnetic pressure. The use of a casting technique could result in an even lower cost, which should be almost independent of the mass of the RTL. A particularly attractive 
option is to use a lithium compound such as Flibe with a chemically compatible metal conductor, since Flibe would be in the reactor anyway to provide cooling and tritium breeding.

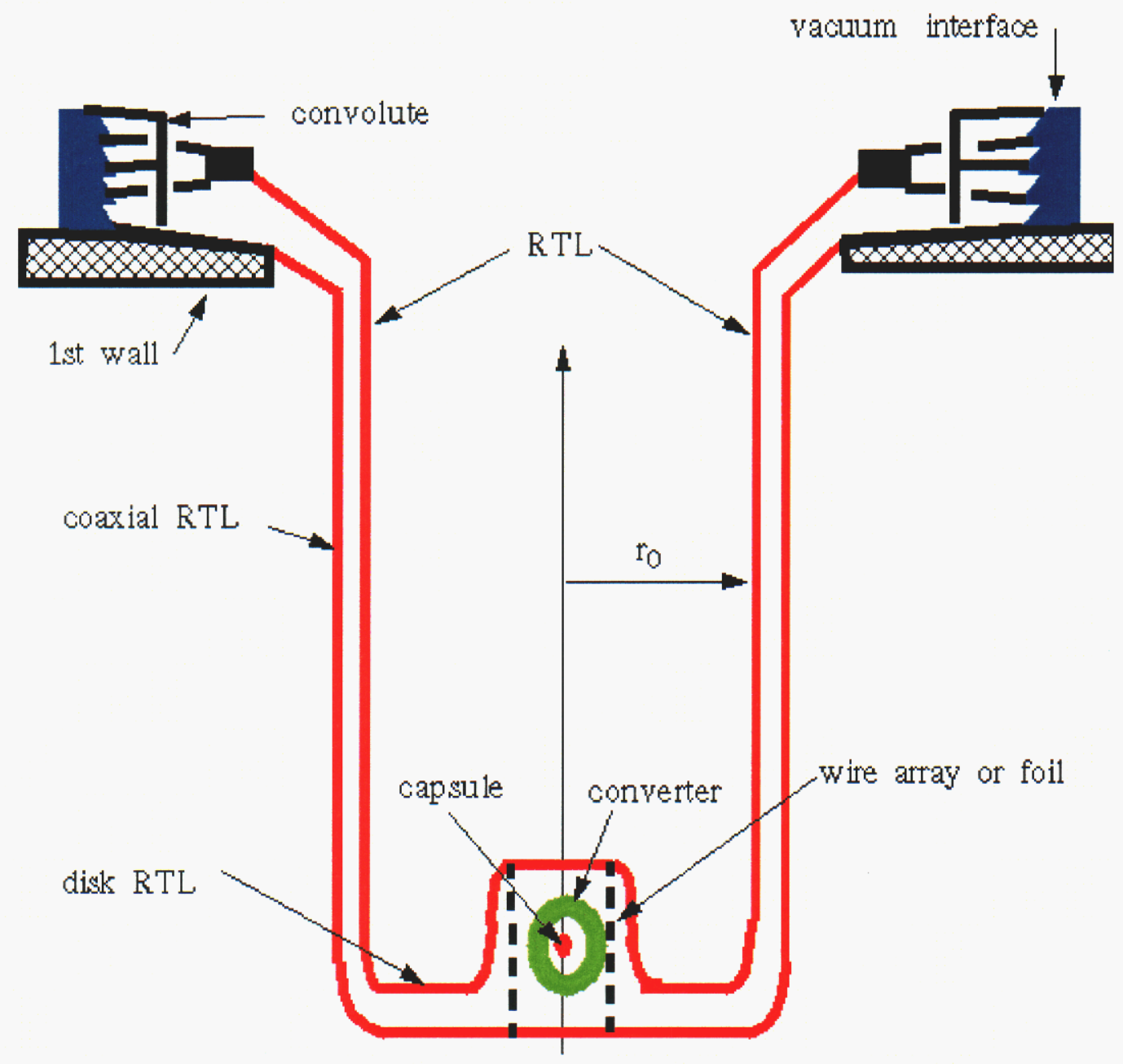

Figure 1. A schematic of a Recyclable Transmission Line (RTL).

Note that the RTL has an advantage over all other existing approaches to ICF and IFE, which is that the RTL does not have to go in a straight line. For example, as shown in Fig. 1, the RTL can have a right angle bend, which allows for shielding the x-rays and 
blast wave from the fusion explosion from the delicate parts of the accelerator (e.g. the convolute and vacuum interface) and the permanent connection hardware. In contrast, a laser or ion driver always has the problem of the last optic element.

Studies indicate that the cost of replacing the damaged transmission line can be significantly below the value of the energy that is produced by the fusion explosion if a low mass transmission line is used $(\sim 1 \mathrm{~kg})$ and the fusion explosion has a relatively high yield ( few GJ). Much larger RTL masses are possible if materials are used which can be separated from other materials within the fusion chamber, and then this recovered material is refabricated into another transmission line. A cost estimate of ( $\$ 0.70 /$ shot) has been made by the Advanced Manufacturing Group at Sandia National Laboratories, assuming that the parts could be fabricated robotically. The cost is essentially independent of the mass if a casting process can be used. Studies have shown that the target chamber can be protected from each fusion blast by suitable liquid and/or solid materials. The use of a lithium-bearing coolant blanket of sufficient thickness will result in (1) absorption of the fusion neutron energy (the primary function for a power plant), (2) breeding of tritium (which is needed for fuel), and (3) protection of the first wall from neutron damage. A material that can accomplish all of these functions is Flibe, which is a salt composed of fluorine, lithium, and beryllium. It may be possible to use Flibe in its solid state as a portion of the RTL. However, Flibe is an insulator, so it will need a coating of a conducting material. Materials such as lead, tin and aluminium can easily be separated from Flibe and are reasonably good conductors. Alternatively, lithium metal or lithium metal alloys ( $\mathrm{LiPb}, \mathrm{LiAl}$ ), could be used. In addition to the conductivity requirement, the cathode side of a transmission line must break down fairly uniformly to result in efficient power flow. For example, aluminum is a better conductor than stainless steel, but does not break down as uniformly as stainless steel.

Therefore, the purpose of the present study was to test the power flow properties of various candidate RTL materials in experiments at power flow levels comparable to those for an IFE z-pinch power plant. These experiments were performed on Saturn at $10 \mathrm{MA}$, and were successful - the results are presented in Section 2. In Sections 3, 4, and 5 , further supporting results from the University of California, Berkeley; the University of California, Davis; and the University of Wisconsin are presented. 


\section{RTL candidate material experiments on Saturn}

The RTL could be constructed out of a lithium bearing power plant coolant such as Flibe (fluorine-lithium-beryllium). Materials such as lead, tin, carbon, and aluminium can easily be separated from Flibe and thus are also good candidate RTL materials. In addition, it may be possible to use Flibe in its solid state as a portion of the RTL. However, since solid Flibe is an insulator, a conductive coating will probably be required. We need to determine if transmission lines constructed from these materials will efficiently transport electrical power at the large currents required of a fusion driver. Specifically, we need to determine if the breakdown behavior of a candidate RTL material has a deleterious effect of power flow efficiency. As an example, aluminum is a excellent conductor and structural material. However, there is some evidence that transmission lines constructed from aluminum transmit power less efficiently that those constructed from stainless steel, due to the nonuniform breakdown of aluminum surfaces. The breakdown appears to be much more uniform if the aluminum is coated with a thin layer of carbon.

The Saturn accelerator was chosen for initial power flow experiments because of the significant cost savings. Saturn can deliver a current of approximately $10 \mathrm{MA}$ at roughly $20 \%$ of the cost/shot for the $\mathrm{Z}$ accelerator. Reactor- scale current densities are produced by using a fairly small transmission line radius. We designed coaxial transmission lines to attach to the Saturn accelerator. An inner electrode (cathode) radius of $4 \mathrm{~cm}$ was chosen for compatibility with the convolute hardware. The anode cathode gap of $3 \mathrm{~mm}$ was chosen to provide high confidence that stainless would provide efficient transport. The length was chosen to be $30 \mathrm{~cm}$ so that the total inductance of the RTL load $(\sim 4.5 \mathrm{nH})$ would not be too high. Experience indicates that loads in excess of $5 \mathrm{nH}$ can cause significant electron loss in the convolute. A schematic of the RTL design is shown in Fig. 2. 


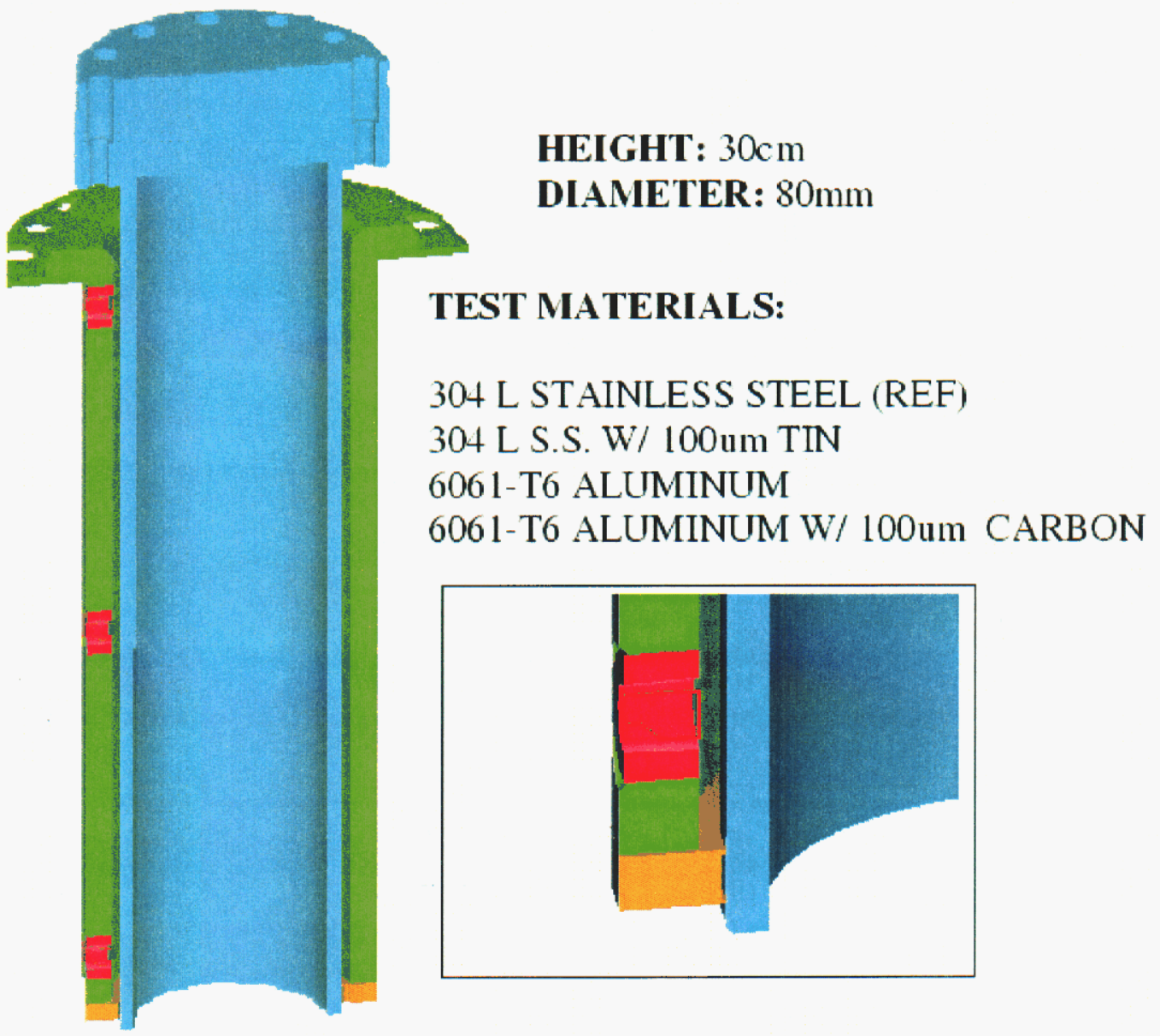

Figure 2. A schematic of the Saturn RTL design.

Stainless steel is considered the preferred material for self-magnetically insulated transmission lines. Unfortunately, stainless steel is comprised of a number of elements which would activate in a fusion reactor. It would also be difficult to separate out all of these materials from the reactor coolant and refrabricate a stainless steel RTL. Therefore we constructed reference RTLs out of stainless to be compared with RTLs composed of other more suitable reactor materials. We would like to test solid Flibe but this was not practical due to cost and health physics issues. Since Flibe will probably need a coating of an electrically-conducting material, we chose to test the conducting material using stainless steel, rather than Flibe, for the structural strength. Tin and lead are the best 
candidates for this purpose. We chose to coat stainless steel with $100 \mu \mathrm{m}$ of tin, which is approximately 1 skin depth. We ruled out lead in these experiments because of its toxicity. Aluminum does not activate excessively, is easily separated from the reactor coolant, and is a good structural material. Previous experiments suggest that the electrical breakdown of aluminium is nonuniform when used as electrodes in a selfmagnetically insulated transmission line. This behavior could possibly reduce the power flow efficiency of an RTL, which is operated near the self-magnetic insulation limit. The breakdown behavior of aluminum appears to be more uniform if it is coated with a thin layer of carbon. Therefore we constructed test RTLs out of aluminum, both with and without a coating of carbon.

The primary diagnostics in these experiments were B-dots to measure the current. Three B-dots were space azimuthally at the top, middle, and bottom of the RTL. We used existing Protodyne B-dots, which we obtained for free. These B-dots had a somewhat larger loop area than would be preferred, but the estimated signal of $1 \mathrm{kV}$ was not expected to breakdown cables or connectors. However, this did require the use of a number of attenuators.

Four Saturn shots were successfully fielded. These shots included two stainlesssteel reference shots, one bare aluminum shot, and one tin-coated stainless-steel shot. The recorded signals are shown for the first stainless-steel shot in Fig. 3. One of the signals in the bottom B-dots clearly broke down, while another of the bottom B-dots was clipped slightly. None of the B-dot signals show a negative excursion, which is necessary to bring the current signals back to zero. The B-dots apparently break down at voltage reversal possibly due to electrons striking the B-dots at this time. Fig. 4 shows the integrated signals. The azimuthal averages are shown in Fig. 5. We removed the signal that appeared to short early from the average for the bottom B-dot monitor. The average of the top is somewhat less than either the middle or the bottom. Clearly, this is not possible, since the current was injected from the top. The conclusion to be drawn is that we could not measure any loss in current for this relatively short $(30 \mathrm{~cm}) \mathrm{RTL}$. A reactor scale RTL would be several meters long. 

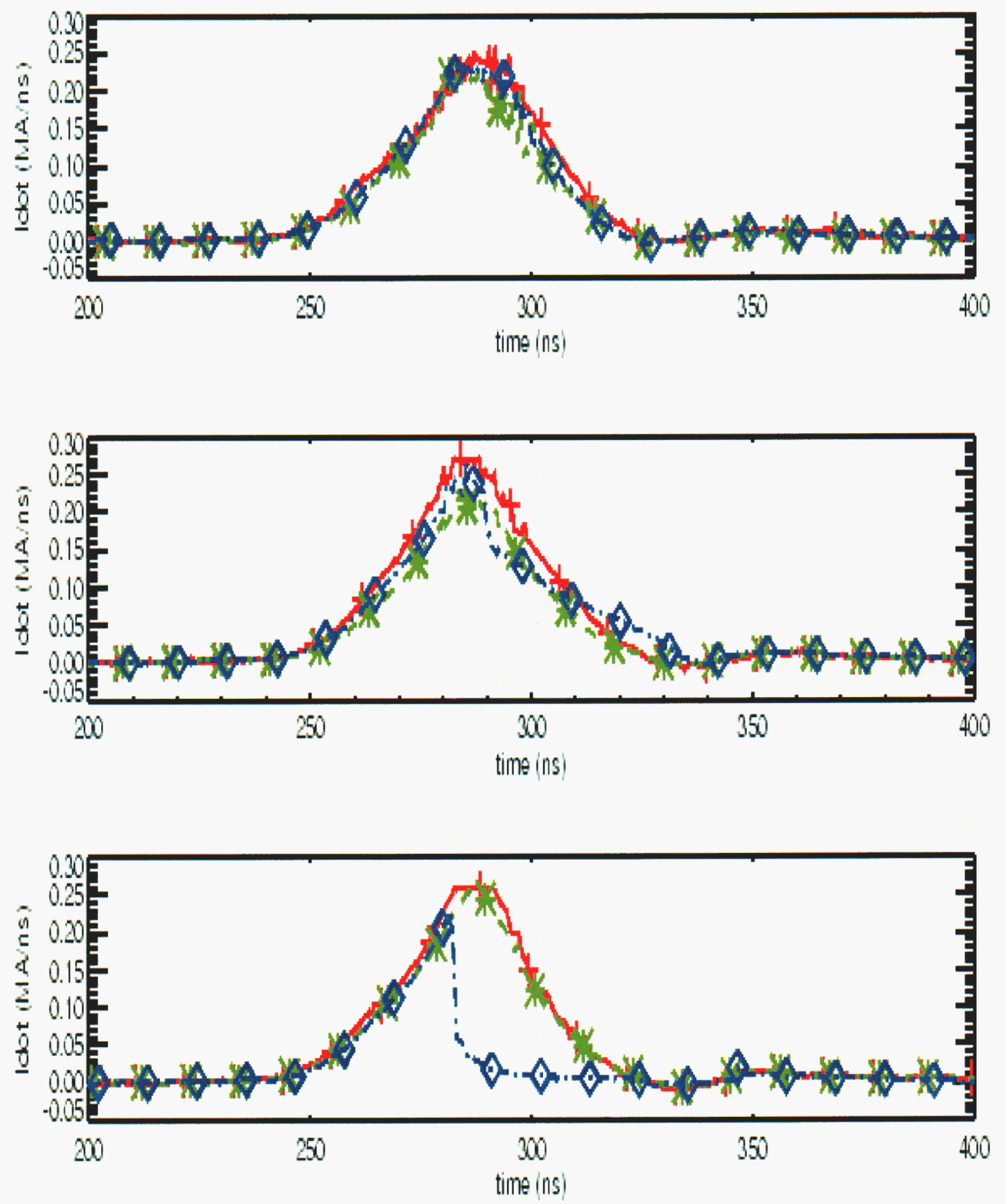

Figure 3. The measured I-dot signals from shot 1 (stainless-steel RTL). 

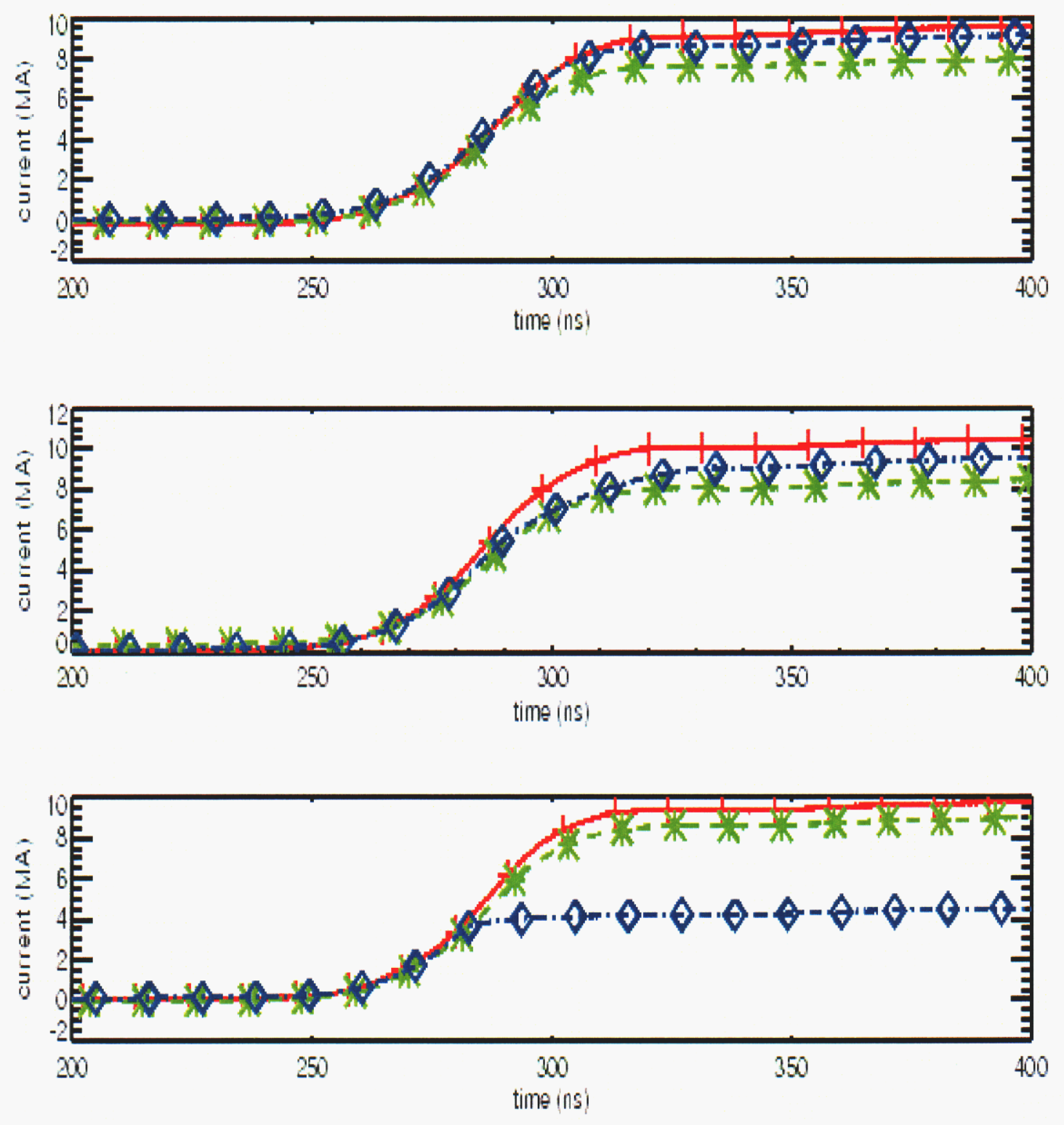

Figure 4. The integrated B-dot signals from shot 1 (stainless-steel RTL). 


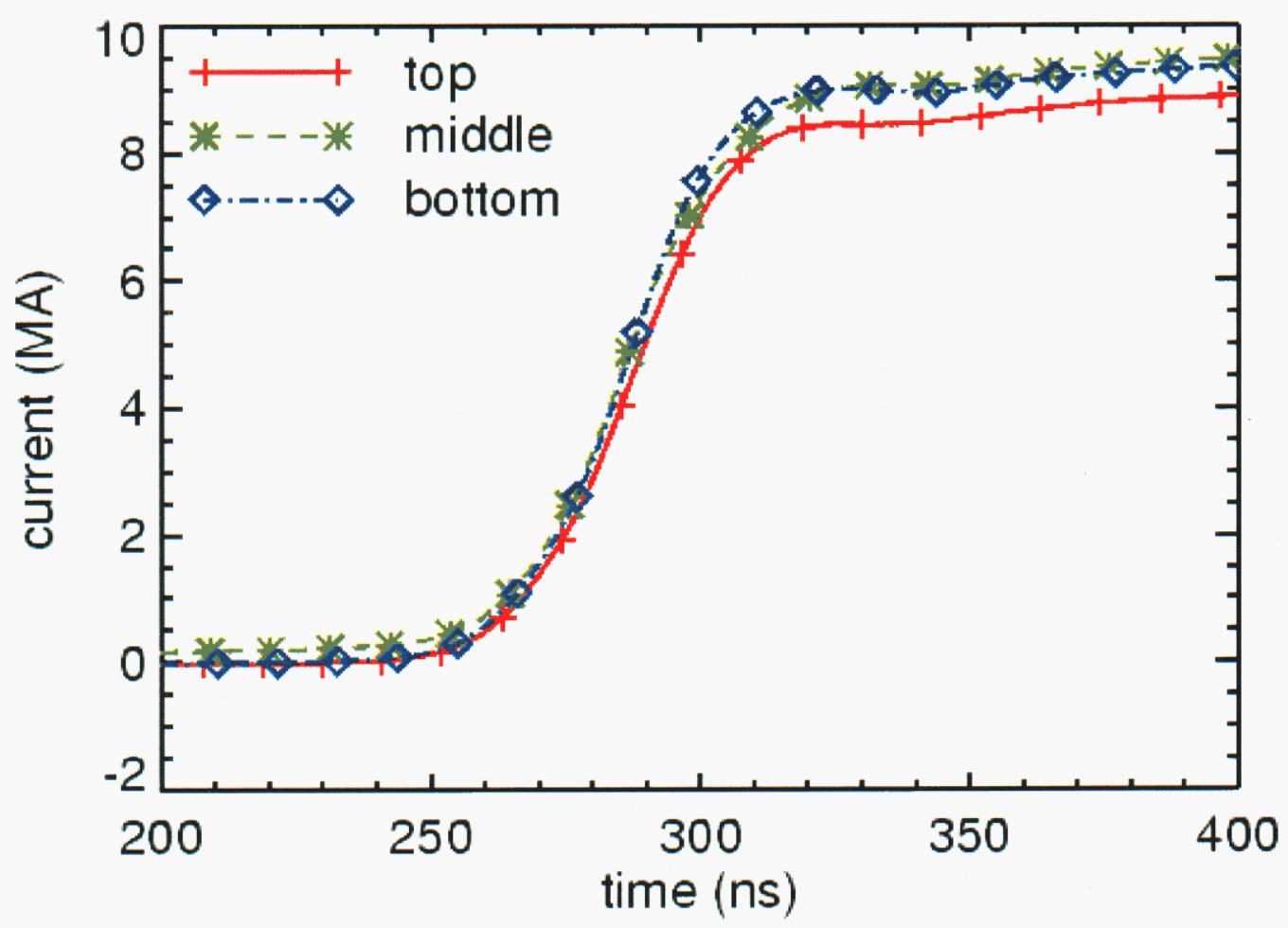

Figure 5. The azimuthally-averaged current for shot 1 (stainless-steel RTL).

The second shot tested a bare aluminum RTL. The I-dot signals are shown in Fig. 6. One of the middle B-dot monitors appears to have shorted early. Otherwise, the data appears to be of the same quality as the first reference stainless steel shot. Integrating these signals and performing an azimuthal average (omitting the shorted B-dot signal), we obtain the curves shown in Fig. 7. The results of Fig. 7 show no indication of current loss over the length of the aluminum RTL. However, it should be kept in mind that the effects of nonuniform breakdown may not be measurable in a transmission line that is only $30 \mathrm{~cm}$ long and has a zero impedance load. Longer RTLs will need to be tested to determine if bare aluminum can be used as an RTL. Since we were unable to see any losses with the bare aluminum, there would be no point in coating the aluminum with carbon in the present experiment. 

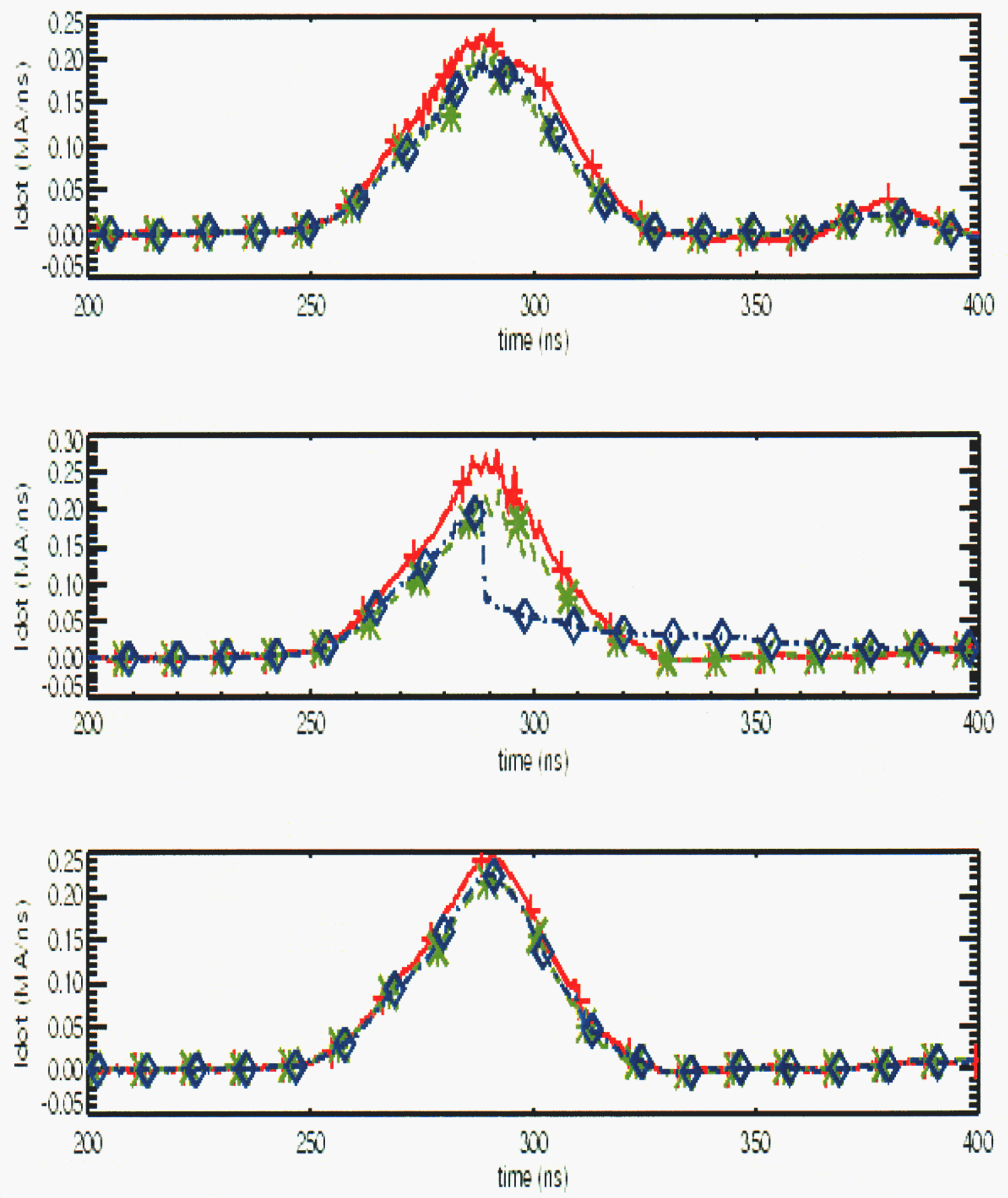

Figure 6. The measured I-dot signals for shot 2 (bare aluminum RTL). 




Figure 7. Azimuthally-averaged currents for shot 2 (bare aluminum RTL).

In the third shot, which was a repeat of the stainless-steel reference shot, most of the B-dot signals indicated premature shorting. The fourth shot tested a tin-coated stainless-steel RTL. The I-dot signals for this shot are shown in Fig. 8. Several of the Bdots show indications of premature shorting. In particular, the blue curve for the middle B-dots and the blue and green curves for the bottom B-dots have clearly shorted. Removing these we obtain the average currents shown in Fig. 9. 

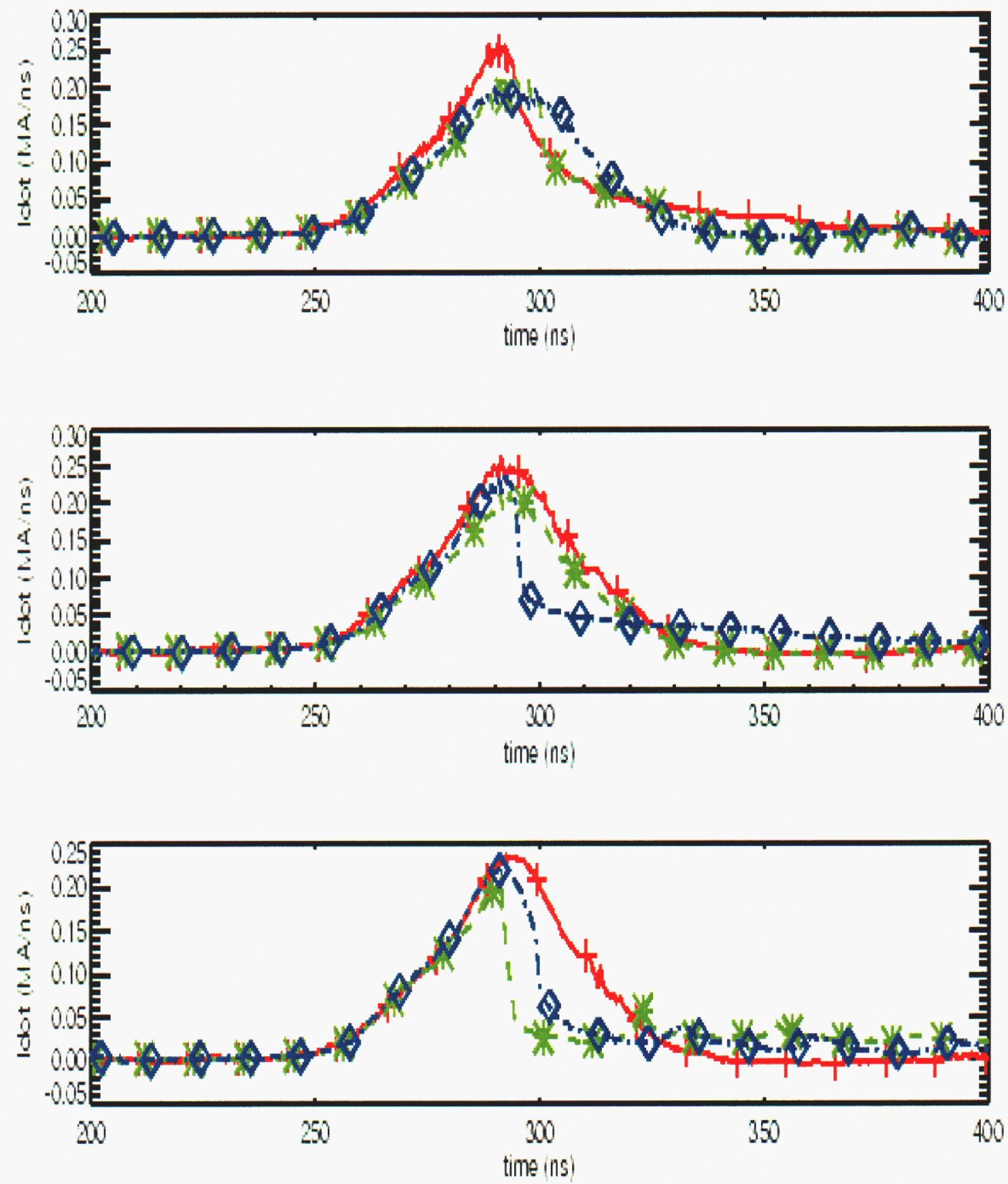

Figure 8. The measured I-dot signals for shot 4 (tin-coated stainless-steel). 


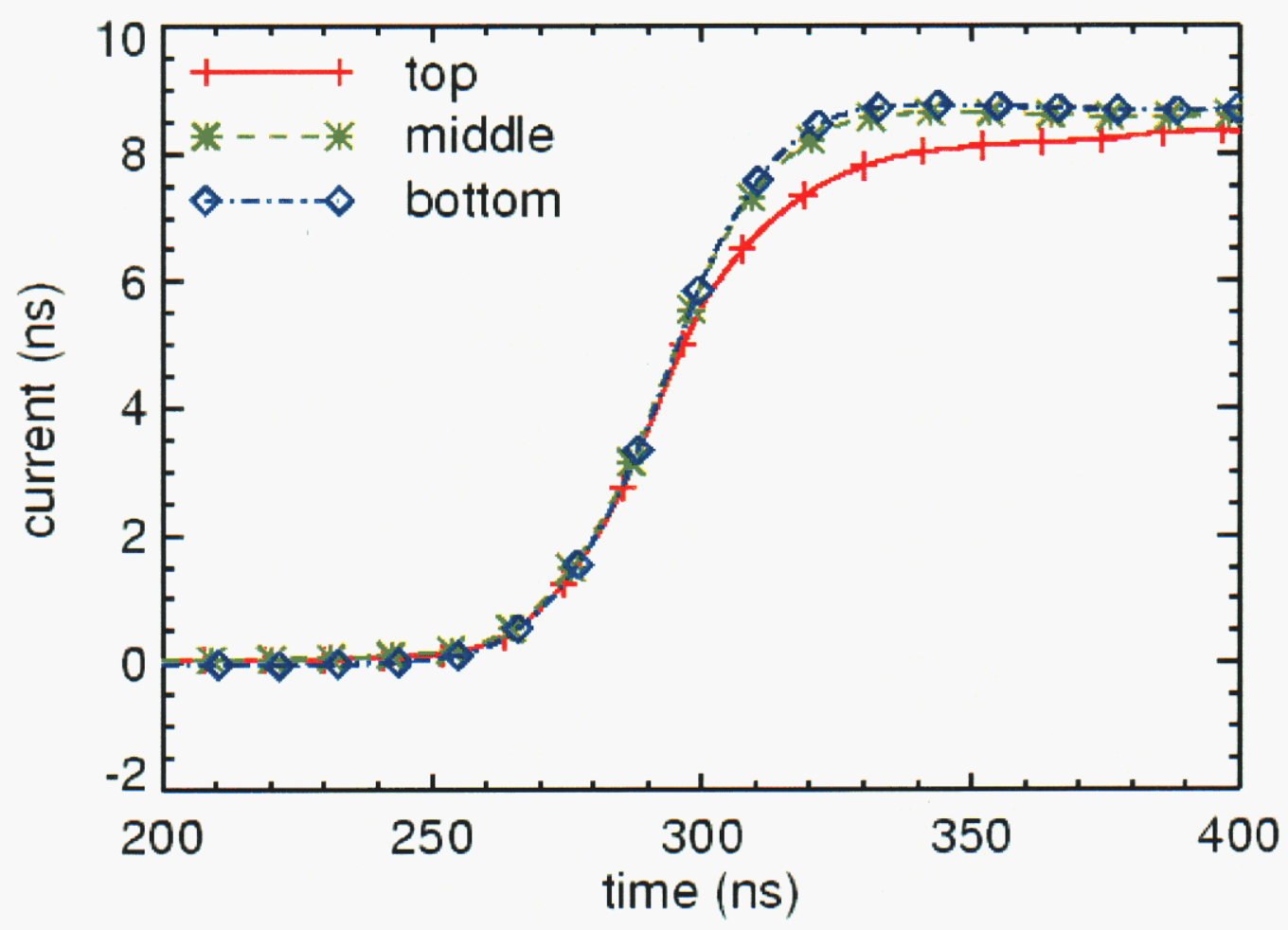

Figure 9. The azimuthally-averaged currents for shot 4 (tin-coated stainless-steel).

There is no indication of current loss in any of the RTL experiments. This is good news in that power flow is apparently not extremely sensitive to the electrode material. However, several things should be kept in mind. First, the RTLs in this experiment were fairly short $(30 \mathrm{~cm})$ when compared to reactor-size RTLs that will be several $\mathrm{m}$. Second, the bottom end of the RTLs in this experiment were shorted. A reactor-scale RTL will have a z-pinch load. Since the total inductance of a reactor RTL will determine the machine driving voltage that is required, this inductance should be minimized. This means that the RTL will operate near the magnetic insulation limit. This may drastically increase the sensitivity of power flow to the choice of electrode material. We will have 
to design tests that are sensitive to these features. Finally, the quality of the data has probably been compromised by the "free" B-dots.

\section{Candidate RTL materials studies at UCB}

Research on potential materials for RTLs has been initiated at the University of California, Berkelely. Potential power plant material coolant material options include lithium; lithium-tin and lithium-lead alloys; and Flibe salt and tin or lead (binary coolant system). Molten Flibe is immiscible with tin and lead, so mixtures of Flibe and tin or lead in an RTL in a power plant could be easily separated. Cast Flibe (melting point of $460 \mathrm{C}$ ) can be used as an insulator. Tin (melting point of $232 \mathrm{C}$ ) and lead (melting point of $327 \mathrm{C}$ ) are conductors. To investigate the feasibility of, e.g., Flibe/tin structures, UCB has fabricated simple, strong, cast Flibe/metal structures.

UCB has successfully built the first binary-coolant structure, having completed the potting of one end of a cylindrical Flibe ingot $(1.5 \mathrm{~cm}$ diameter, $5 \mathrm{~cm}$ long) into a copper cup containing molten tin inside a glove box. The copper cup radius was $2 \mathrm{~mm}$ larger than the Flibe cylinder, so the tin joint is clearly visible as shown in Figure 10. As anticipated, the tin has a meniscus with the Flibe that looks much like that formed by mercury in a glass tube. Based on comparison of the O.D. of the Flibe ingot and the I.D. of the quartz test tube used to cast the ingot, we estimate that the flibe thermal expansion coefficient is about $1 / 3$ the expansion coefficient of tin or lead. Thus, in cooling from the tin melt temperature to room temperature, we generated a shrink fit around the Flibe ingot, and the ingot appears to be strongly, mechanically fixed. Figure 10 shows a Flibe ingot potted with tin (top) and with lead (bottom).

Chemically-compatible, non-wetting mold materials are also available with thermal expansion coefficients both greater than (stainless-steel, beryllium) and less than (tantulum, graphite, fused quartz) Flibe. The availablity of these materials suggests that constructing casting equipment to create Flibe parts should be relatively easy. 


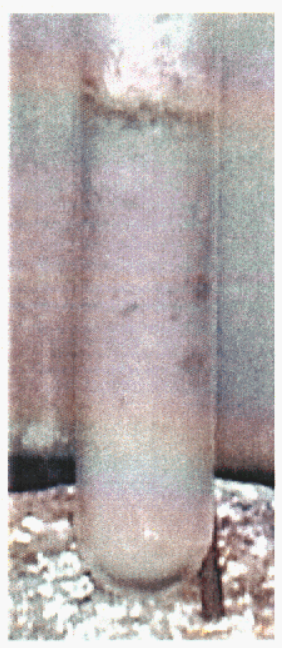

(a) Casting

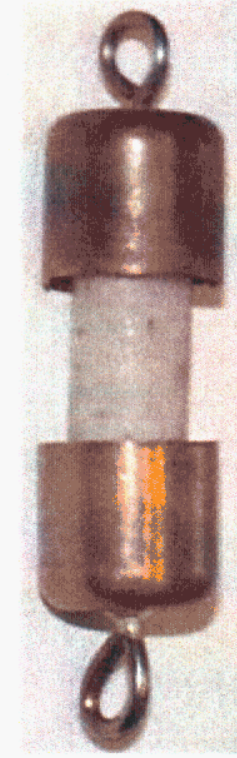

(b) Fabrication



(c) Strength Test

Figure 10. Flibe ingot $(1.5 \mathrm{~cm}$ diameter) cast in quartz test tube. The tensile test structure was fabricated by potting with tin (top) and lead (bottom).

\section{Direct MHD conversion concept at UCD}

One option for the rep-rated, z-pinch power plant concept is to directly convert most of the fusion energy to electricity. This could result in a higher efficiency power plant that generates electricity at lower cost. The University of California, Davis has undertaken a study to evaluate the potential advantages of using direct conversion in a $\mathrm{z}$ pinch driven IFE power plant.

A conceptual design of a z-pinch driven IFE power plant with Compact Fusion Advanced Rankine (CFARII) MHD direct conversion ${ }^{3,4,5}$ has been completed. The CFARII power plant has three advantages over conventional steam plant designs. First, the gross electrical generation efficiency can be as high as $60 \%$. Second, the blanket is close the fusion target, therefore the mass of material required to protect the fusion chamber walls is one to two orders less than in conventional designs. And, third, the Balance of Plant (BoP) costs, i.e., costs other than the reactor costs, are very low compared to conventional power plants (contributing only $3 \mathrm{mils} / \mathrm{kWh}$ to Cost of 
Electricity, CoE). The key requirement for a CFARII reactor is that the fusion yield must be high enough to ionize and heat the compact blanket to working temperatures of $\sim 1 \mathrm{eV}$ in the reactor chamber. Working temperatures this high are required so that the MHD converter operates efficiently. Another condition on the compact blanket is that the thickness must be a few neutron energy mean-free paths thick to absorb most of the fusion energy. These two conditions place a lower limit on the fusion yield that can be used in the CFARII design. It is found that a competitive power plant could be built with a Cost of Electricity $(\mathrm{CoE}) \approx 38$ mills/kWh for a compact blanket of Lithium Hydride and a fusion yield of 1.6 GJ. This result is based on an assumed target-driver figure of merit, $\mathrm{R}_{\mathrm{TD}}=$ fusion gain/driver unit cost $=4 \mathrm{Yield} \mathrm{J} /$ driver $\$$. This figure of merit results from an estimated rep-rated accelerator unit cost of $20 \mathrm{~S} / \mathrm{J}^{6}$ and a target gain $\mathrm{G}=80^{7}$. It is also find that a much higher figure of merit $\left(\mathrm{R}_{\mathrm{TD}} \sim 20 \mathrm{~J} / \$\right)$ is required for low electricity cost (44 mills/kWh) with a Flibe blanket. The parameters for a conceptual design for a 1 GWe power plant are presented in Table1.

Table 1. Conceptual design for a nominally 1 GWe CFARII II z-pinch power plant with a lithium hydride blanket, where the average fusion power, $\mathrm{P}_{\text {fusion }}=2.5 \mathrm{GW}$; driver efficiency, $\neg_{\text {driver }}=0.2$; fusion gain, $G=80$; and the driver cost, $C_{\text {driver }}=20 \$ / J, R_{\mathrm{TD}}=4$ $\mathrm{J} / \$$.

\begin{tabular}{|l|c|c|}
\hline Fusion yield & $1.6 \mathrm{GJ}$ & $3.2 \mathrm{GJ}$ \\
\hline Time between pulses & 0.6 & $1.2 \mathrm{sec}$ \\
\hline Blanket outer radius, $\boldsymbol{r}_{\text {outer }}$ & 15 & $20 \mathrm{~cm}$ \\
\hline Pressure vessel minor radius $\mathrm{r}_{\mathrm{c}}$ & $3 \mathrm{~m}$ & $4 \mathrm{~m}$ \\
\hline Blanket fusion energy capture fraction, $\mathrm{F}_{\mathrm{c}}$ & 0.9 & 0.95 \\
\hline Accelerator energy delivered to the load & $25 \mathrm{MJ}$ & $50 \mathrm{MJ}$ \\
\hline X-ray yield & $20 \mathrm{MJ}$ & $40 \mathrm{MJ}$ \\
\hline Driver direct cost & $0.500 \mathrm{G} \$$ & $1 \mathrm{G} \$$ \\
\hline Total plant direct cost & $1.1 \mathrm{G} \$$ & $1.6 \mathrm{G} \$$ \\
\hline Total capital cost & $1.9 \mathrm{G} \$$ & $2.8 \mathrm{G} \$$ \\
\hline Net Electrical power & $1.2 \mathrm{GWe}$ & $1.3 \mathrm{GWe}$ \\
\hline Net cycle efficiency, ${ }_{\text {net }}=\mathrm{P}_{\text {net }} / \mathrm{P}_{\text {fus }}$ & $46 \%$ & $50 \%$ \\
\hline CoE & $38 \mathrm{mills} / \mathrm{kWh}$ & $48 \mathrm{mills} / \mathrm{kWh}$ \\
\hline
\end{tabular}




\section{Rep-rated z-pinch power plant concept development at U. Wisconsin}

The rep-rated z-pinch power plant concept requires optimzation of the power plant coolant blanket material and thickness to provide efficient energy conversion, tritium breeding, and neutron protection for the first wall. The University of Wisconsin has performed several calculations concerning the coolant blanket, neutron shileding effects, and overall chamber activation. Here, we give a brief summary of some of the blanket calculations that show several advantages of the rep-rated, z-pinch power plant concept.

In order to calculate the required blanket thickness for proper energy conversion and tritium breeding, a simple 1-D spherical model was developed, similar to that developed and studied by Sahin et al ${ }^{8}$ The model consists of a spherical shell of breeder material with a $5 \mathrm{~cm}$ inner radius and a shell thickness, $\Delta \mathrm{R}$, up to $200 \mathrm{~cm}$. The blanket materials studied were lithium (Li), a lithium-lead mixture of $83 \%$ lead and $17 \%$ lithium by mass $(\mathrm{Pb}-17 \mathrm{Li})$, and the molten salt Flibe with a chemical symbol defined by $(\mathrm{LiF})_{2}\left(\mathrm{BeF}_{2}\right)$. The neutron scattering and tritium breeding calculations were conducted in $\mathrm{COG}^{9}$, an arbitrary geometry Monte-Carlo neutron and photon particle transport code developed at LLLNL for deep neutron penetration studies. COG uses the ENDL and EPDL cross-section libraries for all neutron and photon interaction calculations and provides an output for the frequency and type of interactions that occur throughout the geometry. The target was modeled as a $14.1 \mathrm{MeV}$ monoenergetic point source at the center of the spherical shell and a delta function in time. Tritium breeding occurs in the blanket through the two lithium nuclear reactions described by:

$$
\begin{aligned}
{ }^{6} \mathrm{Li}+\mathrm{n} & \rightarrow{ }^{4} \mathrm{He}+{ }^{3} \mathrm{H} \\
{ }^{7} \mathrm{Li}+\mathrm{n} & \rightarrow{ }^{4} \mathrm{He}+\mathrm{n}+{ }^{3} \mathrm{H} .
\end{aligned}
$$

For blanket thicknesses, $\Delta \mathrm{R}$ up to $200 \mathrm{~cm}$, results for the tritium breeding ratio (TBR), energy efficiency, and neutron shielding are shown in Fig.11. The best 


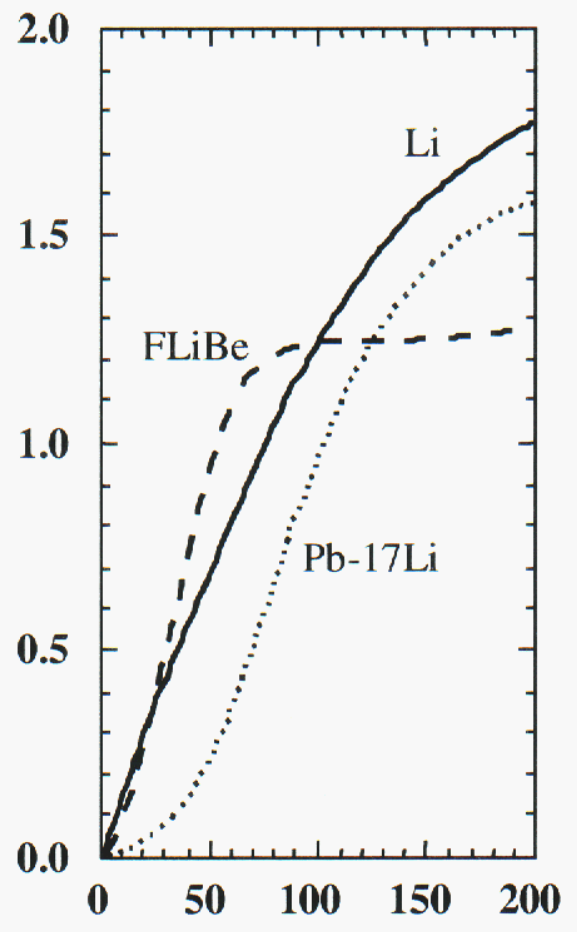

(a)



(b)

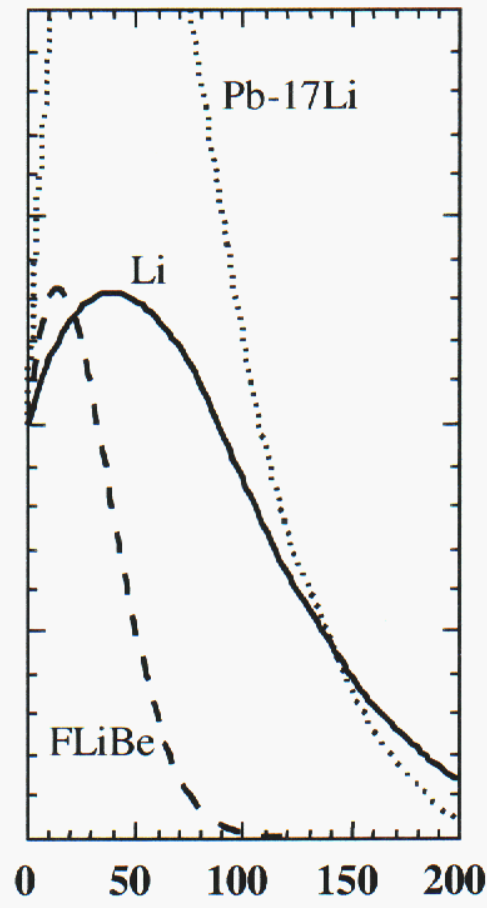

(c)

Figure 11. COG calculations of the (a) tritium breeding ratio, (b) energy conversion ratio, and (c) neutron shielding effectiveness. The energy conversion ratio is calculated by taking the ratio of the energy deposited in the blanket to the total released fusion energy, while the shielding effectiveness is determined by taking the ratio of the COG calculated fluence at the blanket edge to the fluence assuming no blanket structure. 
alternative in all the categories of Fig. 11 is Flibe, where an $80 \mathrm{~cm}$ blanket has a TBR of 1.2 , an energy conversion ratio of 1.08 , and a flux reduction factor of 0.08 . It is of particular interest that the energy conversion ratio is over 1 in this case. This is due to the positive $Q(n, T)$ and (n,n'T) neutron interactions which occur in the Flibe. The obvious temptation is to consider only Flibe as the blanket material not only because it has favorable neutronics parameters, but also because the fluorine makes it less reactive with the structural materials. Flibe has been manufactured and tested in small quantities, but the overall properties are not as well understood as those of Li metal. Li should also be considered because of the additional safety complications associated with the Be in Flibe, and because the Li TBR can be raised far above 1.2. The bottom line here is that it is too early to tell which material will prove to have better characteristics in a power plant, and therfore both the natural $\mathrm{Li}$ and Flibe blankets should be considered at this time.

\section{Conclusions}

Experiments were successfully completed on the Saturn accelerator at $10 \mathrm{MA}$ to test several candidate RTL materials for the rep-rated z-pinch power plant concept. These experiments were performed with a model RTL coaxial transmission line of diameter 8 $\mathrm{cm}$, length $30 \mathrm{~cm}$, and gap width $3 \mathrm{~mm}$. Materials tested included stainless-steel, aluminum, and a tin coating on stainless steel. The purpose of the experiments was to investigate the uniformity of the electrical turn-on of the RTLs. Three sets of three azimuthally placed B-dots were used to measure the current. The azimuthal current readings were essentially identical, and there was no indication of current loss in any of these cases. These are important initial results that are very favorable for the RTL reprated, z-pinch, power plant concept.

Supporting work was also performed by our collaborators at three universities. At the University of California, Berkeley, initial studies of candidate RTL materials were performed. The power plant coolant material Flibe (containing flourine, lithium, and beryllium) was investigated, and small samples were cast to examine their structural characteristics with coatings of other materials (such as lead). At the University of 
California, Davis, initial studies of direct MHD conversion were performed. It was found that a competitive power plant with a $1.6 \mathrm{GJ}$ target yield could be built using a zpinch driver with a compact blanket of lithium hydride for direct MHD conversion. At the University of Wisconsin, initial studies of the rep-rate z-pinch power plant concept were performed, including analysis of the tritium-breeding ratio, energy conversion efficiency, neutron shielding properties, and activation analysis. All of these results are very encouraging, and are already demonstrating several of the advantages of the RTL rep-rated z-pinch power plant concept over other existing IFE concepts (heavy ions and lasers).

\section{References}

1. R. B. Spielman, "Z-Pinch Fusion for Energy Applications," Sandia National Laboratories Report SAND99-3155 (1999).

2. R. Hawryluk, G. Logan, and M. Mauel, "Proceedings of the 1999 Fusion Summer Study," Snowmass, CO, July 11-23, 1999 (1999); C. L. Olson, Comments on Plasma Phys. Controlled Fusion, Comments on Modern Physics 2, 113 (2000).

3. B. Grant Logan, Fusion Technology 20, 992 (1991).

4. B. Grant Logan, Fusion Technology 21, 1784 (1992).

5. B. Grant Logan, Fusion Engineering and Design 22, 151 (1993).

6. R. B. Spielman, private communication (1999).

7. J. H. Hammer, M. Tabak, S. C. Wilks, J. D. Lindl, D. S. Bailey, P. W. Rambo, A. Toor, and G. B. Zimmerman, Phys. Plasmas 6, 2129 (1999).

8. S. Sahin, R. W. Moir, J. D. Lee, and S. Unalan, Fusion Technology 25, (1996).

9. T. Wilcox and E. Lent, COG Home Page: http://www-phys.Ilnl.gov/N Div/COG/Manual/COG ToC.html, 10/20/00. 


\section{Distribution}

1 Prof. Per F. Peterson

Dept. of Nuclear Engineering

4111 Etcheverry

University of California

Berkeley, CA 94720-1730

1 Prof. John S. De Groot

Department of Applied Science

University of California, Davis

One Shields Avenue, 228 Walker Hall

Davis, CA 95616

1 Dr. Robert R. Peterson

Dept. of Nuclear Engineering and Engineering Physics

Fusion Technology Institute

University of Wisconsin

1500 Engineering Drive

Madison, WI 53706

$\begin{array}{rrrl}1 & \text { MS-0188 } & 4523 & \text { C. E. Meyers } \\ 1 & \text { MS-0513 } & 1000 & \text { A. D. Romig } \\ 1 & \text { MS-0724 } & 6000 & \text { R. J. Eagan } \\ 1 & \text { MS-0839 } & 16000 & \text { G. Yonas } \\ 1 & \text { MS-0736 } & 6400 & \text { T. E. Blejwas } \\ 60 & \text { MS-1190 } & 1600 & \text { C. L. Olson } \\ 1 & \text { MS-1190 } & 1600 & \text { J. P. Quintenz } \\ 1 & \text { MS-1191 } & 1600 & \text { M. K. Matzen } \\ 1 & \text { MS-1194 } & 1640 & \text { D. H. McDaniel } \\ 1 & \text { MS-1194 } & 1644 & \text { R. B. Spielman } \\ 1 & \text { MS-1194 } & 1644 & \text { W. A. Stygar } \\ 10 & \text { MS-1186 } & 1674 & \text { S. A. Slutz } \\ 1 & \text { MS-1196 } & 1677 & \text { G. A. Rochau } \\ 1 & \text { MS-0748 } & 6415 & \text { G. E. Rochau } \\ 1 & \text { MS-0839 } & 16000 & \text { M. S. Derzon }\end{array}$


1 MS-9018 8945-1 Central Technical Files

2 MS-0899 9616 Technical Library

1 MS-0612 9612 Review and Approval Desk for DOE/OSTI 